\title{
SAN CARLO DEI BARNABITI: RESTORATION AND REINFORCEMENT OF THE ROOFING OF A FLORENTINE BAROQUE MASTERPIECE
}

\author{
Claudio Mastrodicasa ${ }^{\mathrm{a}}$, Simone Montecchi ${ }^{\mathrm{a}}$, Grazia Tucci ${ }^{\mathrm{b}}{ }^{*}$, Alessandro Conti $^{\mathrm{b}}$, Lidia Fiorini $^{\mathrm{b}}$ \\ ${ }^{\text {a }}$ Department of Technical services, Municipality of Florence - direz.servizi.tecnici@comune.fi.it \\ ${ }^{\mathrm{b}}$ GECO Lab., University of Florence - DICEA Dept., Via P.A. Micheli, 8, Florence - grazia.tucci@unifi.it
}

KEY WORDS: San Carlo dei Barnabiti, 3D modelling, Displacement maps, Basalt fibre reinforcement, Truss end replacement, Lath and plaster.

\begin{abstract}
:
The church of San Carlo dei Barnabiti houses one of the most important examples of Baroque illusionistic painting in Florence. Given the level of deterioration of the vault, the preliminary investigations required a 3D survey of the current geometry to detect the mainly damaged areas. A point cloud obtained by laser scanning is employed to investigate the deformations and the state of conservation of the vault. The acquired data also revealed some unknown aspects concerning the construction of the structure and its pictorial decoration useful to design the restoration project.
\end{abstract}

\section{INTRODUCTION}

The widespread use of 3D digital models of architectural complexes for different purposes show their virtually limitless potentialities and applications. Even though some consolidated workflows are already in use to produce and process 3D spatial data, it is however essential to identify on a case by case basis the most suitable procedures to enhance the peculiarities of every site. In this case study, the point cloud generated by the laser scanner is employed to investigate the deformations and the state of conservation of the vault during the various stages leading to its restoration. The acquired data also revealed some unknown aspects concerning the construction of the structure and its pictorial decoration.

\section{HISTORICAL NOTES}

The building complex of San Carlo dei Barnabiti, made up of the church having the same name and the convent, is located in Via Sant'Agostino, in the centre of Florence, in the block between Via Maffia and Via dei Serragli. This religious building was built in 1636 by Gherardo Silvani, who is considered one of the most prolific architects of the $15^{\text {th }}$-century Florentine scene, as well as the father of "Florentine Baroque", i.e. a less bizarre and eye-catching version of Baroque, the style that conquered Rome and the South of Italy in those days.

The work commissioned to Silvani by the Clerics Regular of Saint Paul (Chierici regolari di San Paolo), also known as Barnabite Fathers, was accomplished in 1640 with the demolition of two row houses and part of a third one next to the ancient little oratory that the Barnabites already owned (Bertani et al. 1995).

The plan of the church (approx. $16 \times 10 \mathrm{~m}$ ) is still visible in the ancient built fabric. This is probably the reason why it was impossible to build the chamber orthogonal to Via di Sant'Agostino; consequently, the façade and counter-façade were built within a trapezoid that included the access stairs to the large window.

Famous artists like Filippo Brilli, Bernardo Ciurini and Giuseppe Zocchi worked at this construction site. In 1747 the latter painted the dome and the spandrels.

As far as the nave vault is concerned, according to the historical researches the church was probably covered by a truss roof. The documents show that in 1720 a barrel vault with side groins made of plastered reed mat was built. The following year Sigismondo Betti painted the "Gloria di San Carlo" in its centre. The groins were infilled in 1742, while the architectural perspective was drawn only in $1757-58$ by Domenico Stagi, specialised in "quadrature".

With the Leopoldine suppression the whole complex became private, then passed to the Scolopi Fathers and finally in 1866 to the Municipality of Florence, which initially used it as a gym and then as a place for cultural activities.

\section{THE SURVEY OF THE VAULT}

The church of San Carlo dei Barnabiti houses one of the most important examples of Baroque illusionistic painting in Florence, which resulted from the collaboration of some of the main 18th-century experts of this artistic form.

The paintings of the nave cover a false "keel" vault. This structure, widely spread between the 17th and 19th century, was supported by ribs formed by boards coupled and nailed broken bonded. The ribs were linked by means of thin rafters and some plastered reed mats were nailed to them. As these are very degradable materials, in case of water leakage the mat can be easily deformed and the painted film, the plaster and the mat itself can fall off.

Given the level of deterioration of the church, the preliminary investigations leading to the restoration work required a 3D survey of the current geometry of the vault to detect the mainly damaged areas. According to the severity of the deformations, 


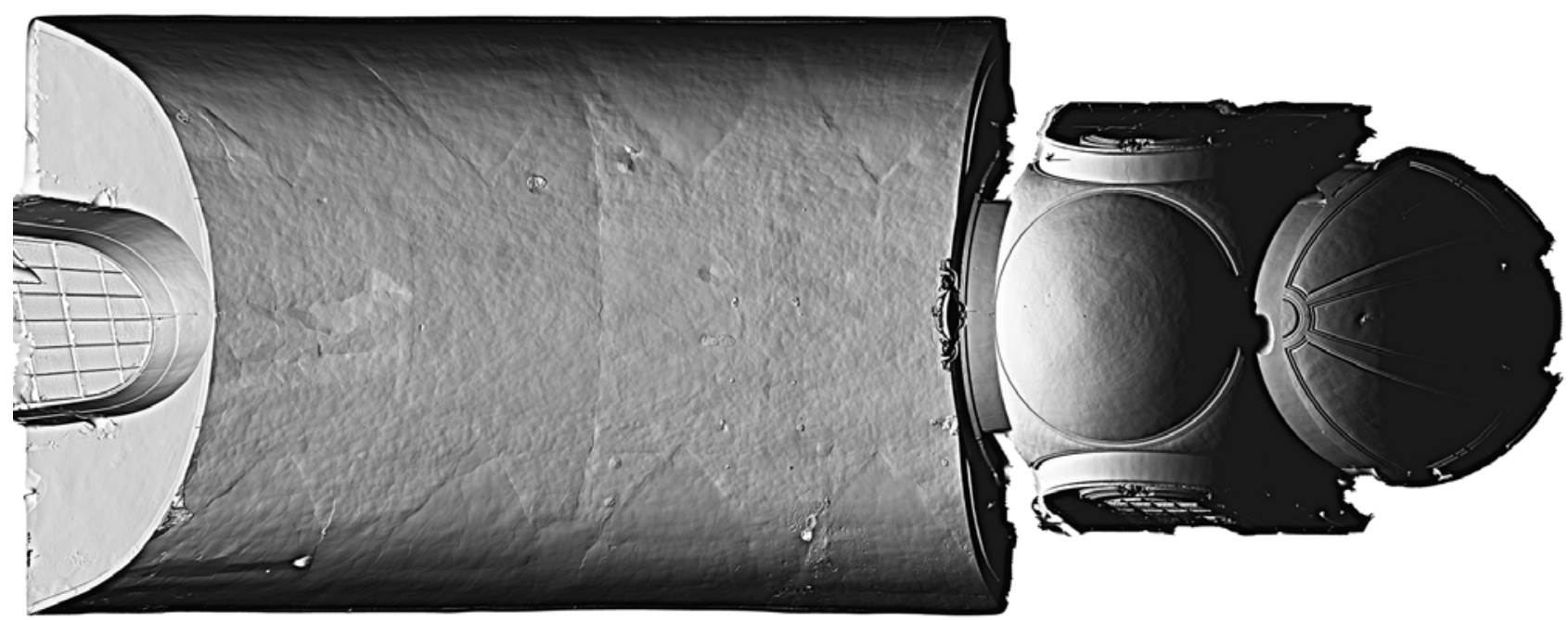

Figure 1. Mesh model of the vault of San Carlo dei Barnabiti showing the infilled groins

restorers will identify the most effective techniques on a pointby-point basis.

As complete scaffolding was already present to perform other preliminary examinations and restoration work, we decided to employ a laser scanner following the already consolidated workflow for this type of surveys. Due to the height of the scaffolding, we had to place the scanner very close to the surface; for this reason, every scan inevitably has an area with very high sampling and big poor quality portions, because the angle between the incident beam and the acquired surface was very acute. Consequently, to obtain uniform sampling we needed to perform 15 scans by selecting the useful parts from each of them.

The result was a point model made up of more than 560 million points, which generated a surface model of more than 76 million triangles describing in detail the nave vault and the dome with spandrels in the presbytery, made of masonry (Tucci and Bonora 2011).

\section{GEOMETRY OF THE VAULT AND DISPLACEMENT MAP}

The method generally used to assess and quantify deformations employs displacement maps obtained by comparing a point or surface model of the current condition to a reference model of the non-deformed condition. If this is not possible, an elementary surface or plane can be used as a reference model. Some software offers specific tools to build horizontal or vertical planes or best fitting planes to a set of points selected by the user. In some cases, it is also possible to build reference surfaces starting from curves with a known equation.

In literature, this type of vaults is called "polycentric", as the ribs have the configuration of arcs of a circle, a geometric construction that can be easily reproduced in a construction site. So, we initially tried to rebuild a similar generating curve starting from a series of transverse sections in order to measure, if possible, the displacement of the real curves compared to it. It turned out that it was impossible to rebuild analytically the theoretical design as the sections cannot be compared to a combination of arcs of a circle or to any other elementary curve. Moreover, the plan is slightly irregular and the height of the vault is variable, so the sections are all different. Anyway, regardless of the design, it is no wonder that such a light and non-rigid structure has progressively settled under its weight since the construction phase.
The reference surface can therefore be suitably modelled only starting from the real generating curves identified during the survey, after having eliminated the deformations due to the subsequent deterioration processes. To this aim, we assumed that the mat was more firmly nailed close to the ribs, resulting in less severe deformations.

However, at least during the initial phase, it was impossible to access the roof space to verify the position of the ribs. So, this element was obtained by examining the created surface model, which unveils some aspects of the vault that cannot be seen to the naked eye. The mesh shows four large triangular areas on each side where the surface of the plaster is more regular, corresponding to the infilling of the pre-existing groins according to the archival documents (Fig. 1). Based on the knowledge concerning the construction of this type of vaults, the main ribs should inevitably be between the groins.

The five sections obtained in the detected areas were approximated with flat spline curves and then a spline surface was built by means of a loft function (Fig. 2). This was used as a reference surface to measure the distance of the point model to produce a displacement map with the algorithm M3C2 (Lague et al. 2013) implemented in (CloudCompare, 2017).

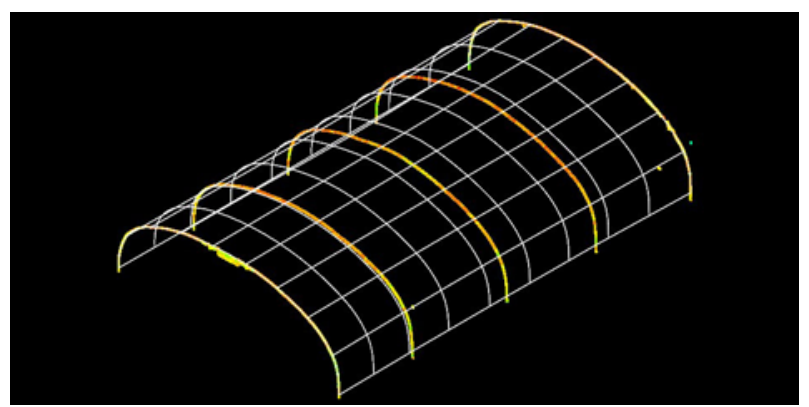

Figure 2 . The spline surface obtained by five cross sections of the vault

Given the empirical system used to determine the reference surface, the less severe anomalies can be ignored, as they are due to a kind of modelling not sufficiently close to reality or to the uneven thickness of the plaster. However, the number of areas in which the geometry deviates significantly from the reference surface is high; so, they should be immediately examined by the restorers to check for possible damage. The maximum deformation is approx. $12 \mathrm{~cm}$. 


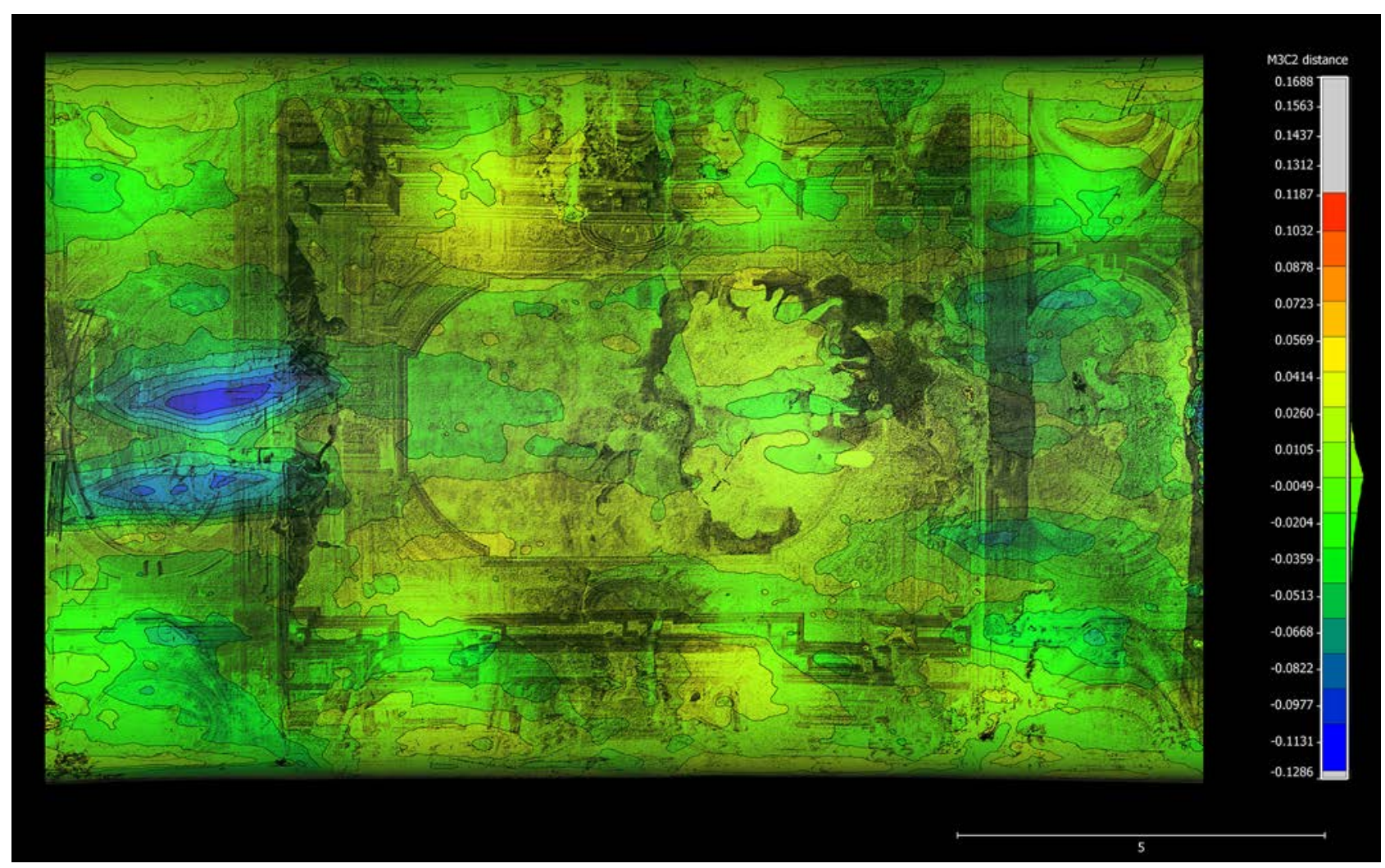

Figure 3. Displacement map between the reference surface and the point model, superimposed on a orthoimage of the vault

The substantial validity of the adopted process has been confirmed by the fact that the displacement map is consistent with the areas where the deterioration is macroscopic and by the visual inspections subsequently carried out in the roof space, which confirmed the position of the ribs and also showed that the wooden structure of the infilled groins is still present. During the restoration work, the survey could be integrated with some acquisitions of the roof space to relate the overhanging structures with what has already been surveyed.

For a quicker localisation of the geometric anomalies, the displacement map has been superimposed to the image of the pictorial decoration (Fig. 3). As is known, terrestrial laser scanners link every acquired point to the corresponding intensity value of the reflected signal, enabling display modes similar to a photograph. This allows us to immediately locate the geometric anomalies by referring them to the pictorial decoration, as well as to point out even small cracks with a width lower than the adopted sampling pitch, hence not represented on the surface model (Tucci et al. 2016).

\section{RESTORATION WORK}

According to the first results of the surveys carried out, we identified a restoration plan affecting mainly the structures of the roof and the roof space to avoid further damage to the vaults of the nave and presbytery. It includes:

1) In situ refurbishment of the end of one of the trusses by building a specific glulam prosthesis with the following techniques:

a) resection of the damaged portion;

b) creation of the glulam prosthesis;

c) connection of the two parts by means of carbon fibre connecting bars.

2) Reinforcement of the extrados of the hemispherical calotte of the presbytery dome: a) shoring of the intrados after placing special protections;

b) levelling of the surfaces with milk of lime and/or lime putty to fill microcracks or fissures;

c) reinforcement by applying basalt fibre ribbons embedded in lime putty to the dome extrados.

3) Reinforcement of the curved ribs supporting the lath and plaster of the nave vault:

a) shoring of the decorated vault after placing special protections;

b) supporting of every single wooden rib with a light metal structure to stiffen it;

c) longitudinal connection of all the ribs by stretching stainless steel cables.

\section{FURTHER DEVELOPMENTS AND CONCLUSIONS}

Additionally, a mesh model representing the real form, freed from the decorative perspective drawn exactly to hide the underlying geometry, shows also the unevenness of the plaster which cannot be seen to the naked eye. Among the unexpected results of the survey, the surface model reveals sketches of the architectural perspective scratched on the plaster, sometimes not congruent with the painting (Fig. 4).

Whether these are evidences of change of mind or traces of a previous frame around the central scene painted by Betti before the intervention of Domenico Stagi, they show that the spatial information undergoing suitable data processing can be used for other purposes compared to the traditional ones in the field of architectural survey (Tucci and Bonora 2015). In fact, it can both provide useful point indications for restoration work and inspire further researches that can lead to a more detailed reconstruction of the history and construction of a building, through suitable archival and diagnostic confirmations. 


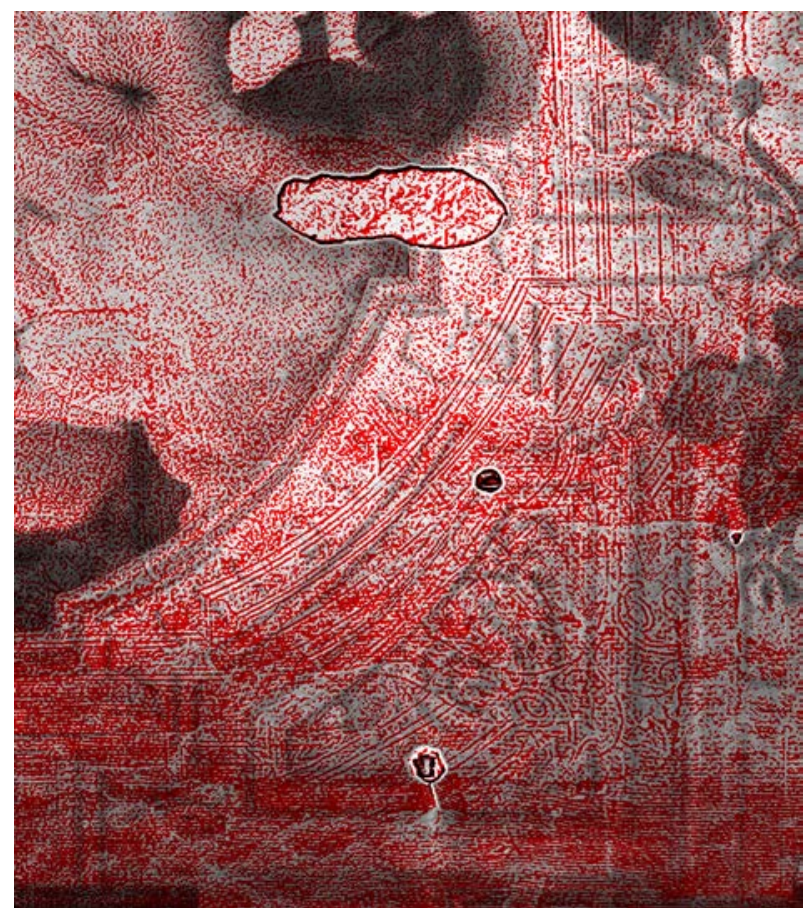

Figure 4. The mesh model showing a sketch scratched on the plaster different from the painting (image processed with Adobe Photoshop's edge enhancement filters)

\section{REFERENCES}

Bertani, L., Cagni, G.M., Castellani, E., Trotta, G., 1995. San Carlo dei Barnabiti a Firenze, I.T.E.A, Anghiari.

CloudCompare (version 2.8) [GPL software]. 2017. Retrieved from http://www.cloudcompare.org/

Lague, D., Brodu, N. and Leroux, J., 2013. Accurate 3D comparison of complex topography with terrestrial laser scanner: application to the Rangitikei canyon (N-Z), ISPRS journal of Photogrammmetry and Remote Sensing

Tucci, G., Bonora, V., 2011. From real to $\cdots$ "real". A review of geomatic and rapid prototyping techniques for solid modelling in Cultural Heritage field. International Archives of the Photogrammetry, Remote Sensing and Spatial Information Sciences - ISPRS Archives, 38 (5W16), pp. 575-582.

Tucci, G., Bonora, V., 2015. Geomatics and management of atrisk cultural heritage. Rendiconti Lincei, 26, pp. 105-114.

Tucci, G., Bonora, V., Fiorini, L., Conti, A. 2016. The Florence baptistery: 3-D Survey as a knowledge tool for historical and structural investigations. International Archives of the Photogrammetry, Remote Sensing and Spatial Information Sciences - ISPRS Archives, 41, pp. 977-984. 